\title{
Ocular complications of systemic steroid after renal transplantation and their association with HLA
}

\author{
H. P. ADHIKARY, ${ }^{1}$ R. A. SELLS ${ }^{2}$ AND P. K. BASU ${ }^{2}$ \\ From 'St Paul's Eye Hospital, Liverpool, and the ${ }^{2}$ Royal Liverpool Hospital
}

\begin{abstract}
SUMMARY The eyes of 62 patients who had received allogenic renal transplants were examined for eye disease. Thirty-six patients were found to have steroid induced cataract. Six patients had ocular hypertension. Twelve patients showed arteriosclerotic changes in their fundi relating to their previous hypertension. There was no significant difference in HLA type in patients who developed cataract and those who did not. 83.3\% of the 6 patients with ocular hypertension had HLA B12 in common. None of the patients had cytomegalic retinitis.
\end{abstract}

Posterior subcapsular cataract as a complication of systemic steroid has been described in the past. ${ }^{1-8}$ Most of the studies have been done on the patients with rheumatoid arthritis, and most of them were in the older age groups. Hardly any studies have been done on younger patients. In this series of younger patients ocular complications have been assessed and their association with particular HLA antigen has been studied.

\section{Materials and method}

This series of 62 patients includes 35 males and 27 females. Their ages varied between 25 years and 60 years, mean 36 years. All the patients had chronic renal failure and had been receiving treatment with regular haemodialysis for a variable period of time between 3 months and $5 \frac{1}{2}$ years before renal transplantation. All the patients had received prednisolone and azathioprine. The steroid regimen was as follows: $150 \mathrm{mg}$ daily immediately after the transplant, reducing by $50 \mathrm{mg}$ every 3 days to a maintenance dose of $50 \mathrm{mg}$ per day, and reducing weekly by $5 \mathrm{mg}$ per day to $20 \mathrm{mg}$ per day and $1 \mathrm{mg}$ monthly to $10 \mathrm{mg}$ per day. Patients with rejection episodes received up to $12 \mathrm{G}$ methylprednisolone intravenously. Any patient with local ocular inflammation was excluded from the series. The haemoglobin, serum calcium, and serum phosphate levels were measured regularly before and after the transplant. None of the patients had any atopic skin conditions or any myopathy or diabetes. HLA typing

Correspondence to $\mathrm{Mr} \mathrm{H}$. P. Adhikary. FRCS. Royal Preston Hospital. Sharoe Green Lane. Preston. Lancs PR2 4HT. was done at the Royal Liverpool hospital. A total of 40 HLA typing sera were used to determine 15 different $\mathrm{A}$ locus antigen specificities and 22 different B locus specificities. Their eyes were examined in detail at St Paul's Eye Hospital after periods of time from 6 months to 5 years. Their visual acuity was recorded, examination was done with ordinary light and the slit-lamp, and fundus examination was done with direct and indirect ophthalmoscopy. Intraocular pressure was measured before and after the dilatation of pupil with phenylephrine $10 \%$. The central and peripheral fields of vision were charted.

\section{Results}

Thirty-six patients were found to have cataracts in their eyes which started after a time varying from one year to 4 years. The cataract was posterior subcapsular in type, starting at the posterior pole. It was bilateral in 29 and unilateral in 7 cases. Most of the patients had good visual acuity, more than 6/12. In one patient bilateral cataracts matured within 3 years of transplantation and required operation.

Six patients had an intraocular pressure more than $22 \mathrm{mmHg}$ on applanation tonometry. These patients were considered to have ocular hypertension. The lowest pressure in this group was at $24 \mathrm{mmHg}$ in one eye of one patient, and highest at $32 \mathrm{mmHg}$ one of another patient. The other 4 patients had an intraocular pressure between the above figures. No pathological cupping of the optic disc was found in this group. Their central visual field was examined in the Bjerum's screen and none showed any defect. When their histocompatibility antigens were studied, 
5 out of $6(83.5 \%)$ patients were found to have HLA $B 12$. The incidence of $B 12$ in patients with normal ocular pressure was $30 \%$.

On fundus examination 5 patients showed some myopic changes. Twelve patients had reactive arteriosclerotic changes in their fundi. One patient had cystoid maculopathy and another had superior temporal vein occlusion. No other abnormality was detected in the fundi in the series.

\section{Discussion}

The high incidence of cataract following long-term steroid therapy has been reported previously. In this series out of 62 patients 36 developed cataract $(58 \%)$. All had high doses of steroids after transplantation. The cataract was in the form of white dots or opacities in the posterior subcapsular region starting at the posterior pole. where the dots were more aggregated. Only in 6 eyes of 3 patients were anterior subcapsular opacities also noted. Although the patients were comparatively young. the incidence of cataract was very high in comparison with the previous report of $23 \%$ in a similar series of patients with renal transplantation. ${ }^{4}$ Since that report immunosuppressive doses have increased, so the incidence of cataract may be dependent not only on the duration of steroid therapy but also on the dose of steroid given. An analysis was therefore done of the number of rejection episodes which necessitated an increase in steroid therapy. The results (Table 1) show no correlation between rejection episodes and incidence of cataract. An examination was also done for the length of time spent on dialysis prior to transplantation in those patients who did or did not subsequently develop cataract. No correlation was found. A comparison was made of HLA antigen distribution in those patients who developed cataract and the patients who did not. Although HLA B7 was found marginally more often in the group with cataract $(16 \%)$ than in the group without cataract $(14 \%)$, no definite association was suggested.

Six patients had ocular hypertension $(10 \%)$, which is significantly higher than in general population. The association of HLA B12 antigen and increased intraocular pressure has been noted in the past. ${ }^{5}$ In this group 5 out of 6 patients $(83 \cdot 3 \%)$ had HLA B12. The incidence of HLA B12 in patients with normal
Table 1 Analvsis of rejection episodes

\begin{tabular}{lllll}
\hline & $\begin{array}{l}\text { Number } \\
\text { of patients }\end{array}$ & $\begin{array}{l}\text { Mean time on } \\
\text { pretransplant } \\
\text { dialvsis (year) } \\
\pm S D\end{array}$ & $\begin{array}{l}\text { Mean no. of } \\
\text { rejection } \\
\text { episodes } \\
\pm S D\end{array}$ & $\begin{array}{l}p \\
(t \text { test }) .\end{array}$ \\
\cline { 1 - 4 } Cataract & 36 & $1.69 \pm 1.69$ & $1.93 \pm 1 \cdot 46$ & NS \\
No cataract & 26 & $1.85 \pm 1.63$ & $2.28 \pm 1 \cdot 60)$ & NS \\
\hline
\end{tabular}

$\mathrm{SD}=$ standard deviation. NS $=$ Not significant .

ocular pressure was $30 \%$. Although the total number of patients with ocular hypertension is small, the presence of HLA B12 in $83.3 \%$ of them is noteworthy.

Reactive arteriosclerotic changes were found in 12 patients suggestive of their previous hypertension. Acute cytomegalic retinitis as a major complication following renal transplant has been reported previously. ${ }^{4}$ It was unusual that none of the patients in this series had suffered from this complication. It could be attributed to the improved screening of blood donors and very high doses of systemic steroids given to the patients during and immediately after the transplant.

We thank Mr R. Mapstone. consultant ophthalmologist. St Paul's Eve Hospital. Liverpool. and $\operatorname{Dr}$ R. M. R. Barnes. Department of Immunology. Roval Liverpool Hospital. for their help.

\section{References}

I Black RL. Oglesby RB. Sallman LV. Bunim JJ. Bethesda. Posterior subcapsular cataracts induced by corticosteroid in patients with rheumatoid arthritis. JAMA 1960): 174: 166-71.

2 Crews SJ. Posterior subcapsular lens opacities in patients on long-term corticosteroid therapv. Br Med J 1963; i: 1644-6.

3 Giles CL. Mason GL. Duff IF. McLean JA. Mick AA. The association of cataract formation and systemic steroid therapy. JAMA 1962: 182: 719-2?

4 Porter R. Crombie AL. Gardner PA. Uldall RP. Incidence of ocular complications in patients undergoing renal transplantation. Br Med J 1972: iii: 133-6.

5 Shin DH. Becker B. The prognostic value of HLA-B12 and HLA$B 7$ antigen in patients with increased intraocular pressure. $A m ~ J$ Ophthalmol 1976; 82: 871-4.

6 Toogood JH. Dyson C. Thompson CA. Mularchyk EJ. Posterior subcapsular cataract as a result of adrenocortical steroid therapy. Can Med Ass J 1962: 86: 52-6.

7 Williamson J. Dalakos TG. Posterior subcapsular cataracts and macular lesions after long-term corticotrophin therapy. $\mathrm{Br} J$ Ophthalmol 1967: 51: 839-42.

8 Williamson J. Paterson RWW. McGavin DDM. Jasani MK. Bovle JA. Doig WM. Posterior subcapsular cataract glaucoma associated with long-term oral corticosteroid therapy. BrJ Ophthalmol 1969: 53: $361-71$ 